\title{
Research on Short News Video Transmission in the Fusion Media Environment
}

\author{
Xulan Ma*
}

Zhejiang University of Finance \& Economics Dongfang College, Haining 314408, China. E-mail: maxulan@126.com

Abstract: In the era of financial media, short videos have developed into a new window of people's understanding at a rapid speed. News short videos meet people's social needs, entertainment needs, and fragmented reading habits, which not only injects fresh blood into the news industry but also challenges traditional news media. However, due to the lack of high-quality productivity, information cocoons, linkage effects, and copyright disputes in short news videos, the development of short video news is hitting a wall now.

Keywords: Fusion Media; Short News Videos; Prospects

\section{The definition of short video and why it is widely accepted by the public}

A short video is a instant music video, which is a method of Internet content transmission. Generally, it is a video transmitted within 5 minutes on the new Internet media. News short videos are usually in the form of a small snippet of news scene combined with voice narration plus text, independent of time and space. With the popularity of $4 \mathrm{G}$ networks, the rapid development of technology, the portability of mobile terminals, and the fast pace of people's lives, the rise of such instant-effective high-traffic product has been determined.

Short videos are widely accepted and used by the public. First, short videos can meet the social needs of users. Video photographers can shoot new things on the media platform anytime, anywhere, without being limited by time and space, satisfying the desire to share. The video recipients watched the video for just a few minutes and commented, and got the satisfaction of communication. At the same time, they could like other people's comment and comment on those who also express opinion on this matter and further gain social recognition. Or it can be shared and forwarded to friends on video platforms or WeChat and Weibo. The input, output, and feedback of this information effectively meet the social needs of users. And new features that are constantly being rolled out, such as "money reward", also make these motivations effective.

Secondly, short videos can meet the entertainment needs of users. Compared with serious text reading, the sound and subtitles of short video fusion add a lot of emotional color to it, which makes people's pursuit of entertainment satisfied while they get informational news. In addition, short videos have gradually become a new window for the public to understand the world, which also directly shows that compared with the circle of friends such as "WeChat Moment", short video transmission actively sends more fresh and novel information to the public.

Furthermore, the era of fragmented reading has arrived. People are accustomed to the form of "short-term, highstimulation" entertainment and reading such as short videos, and faced with "long-term, low-stimulation" reading methods such as reading long stories and watching news channels, it becomes difficult to focus. Media users' attention has also become scarcer, and fragmentation of information ultimately leads to fragmentation of attention. The short video duration is usually within two minutes and is not restricted by time and space, which just meets the needs of media users for fragmented reading.

This is an open-access article distributed under the terms of the Creative Commons Attribution Non-Commercial License (http://creativecommons. org/licenses/by-nc/4.0/), which permits unrestricted non-commercial use, distribution, and reproduction in any medium, provided the original work is properly cited. 


\section{The development issues of short video news compared to traditional media}

\subsection{Information cocoons effect}

Media platforms such as short videos have become the main source for mass netizens to obtain people's livelihood news and entertainment information. On the one hand, platform has used social networks to obtain a large user group, and it has used algorithmic technology to achieve efficient information distribution. On the other hand, under the influence of business-driven and user-oriented values, in order to retain more users, the professional value of platform content dissemination is often compromised with commercial value, making it difficult to become a practitioner of serious news. Platform media not only has problems such as distortion, entertainment, emotion, and fragmentation in the content, but relying solely on the artificial intelligence push of the platform media can easily lead to cognitive information cocoon. When people post information, they only show others what they want others to see and gain the attention of others. The public is also very addicted to this pseudo-environment, and they feel comfortable in the pseudo-environment and cannot distinguish between virtual and reality. Therefore, current political news and serious news in professional media are still irreplaceable in the dissemination of major events.

\subsection{Insufficient quality productivity}

On the one hand, short videos and other We-media pursuit of commercial value, professional value is squeezed. In pursuit of click-through rate, play volume, exaggerated titles and content, mis-attribution and other bad habits prevail. In order to Retain more stable users, a We-media needs to have its own narrative style and characteristics, resulting in the news left by users after viewing is less impressive than the video itself. On the other hand, the rising media is not sensitive enough to news and is limited by the professional ability of journalism. In a serious sense, it does not have the qualifications for high-quality news production. Traditional media has professional news productivity, but is unfamiliar with new communication methods, and it is difficult to combine the two.

\subsection{The linkage effect caused by multi-platform distribution leads to widespread dissemination and difficult rumor removal}

In order to expand their influence, the media usually opens accounts on different platforms, and the same news material is processed with minimal processing or distributed to different platforms intact. With the trend of platformization, the cross-platform and multi-channel communication of news media has become increasingly mature. Coupled with the features of short video, instant-effective and high-traffic, and relying on the advantages of Internet technology, these short video news content will be accurately delivered to our mobile terminals in a very short time, so as to achieve the spread of large-scale debris. The content of these short videos that mostly pursue "premiere and fresh" is usually not considered carefully, and the authenticity of the news content itself is often ignored by the receiving users. It makes users "emotional" and makes it more difficult to find rumors in the future. Many official media have not serialized subsequent clarification videos after the official clarification. Even if a clarification video is posted, it has a much lower clickthrough rate than previously reported videos.

\subsection{Copyright disputes}

In some news short videos, it is inevitable to use the original videos uploaded by netizens. Except for videos of some social events and social phenomena, these non-profit, non-commercial uses can be exempted from criticism about the copyright of the original video. However, some users signed a contract with the platform, and the created video is exclusive to their platform. Even with the exclusive watermark, the source still has bad media to erase the watermark, or does not indicate the source when forward the video, or uploads it to its account intact. Such infringements and thefts are endless.

\section{Suggestions and prospects for the development of short video news}

The $5 \mathrm{G}$ era is coming, and the development of short video news is booming. This type of new type of communication with strong timeliness, leaving commentary without text, and expressing emotions directly becomes a 
way of interpersonal communication. This will also make short video news take people's attention for a long time in the future.

\subsection{Focus on innovation and actively explore high-quality productivity}

Innovation is the source of wealth. The essence of improving short video news is to improve the quality of video content. Transform labels from high-traffic to high-quality, base the balance between timeliness and content integrity, and strive to be realistic and objective.

\subsection{Encourage talent transformation}

The current talent structure of traditional media does not match the talent needs of news production. Talent is at the core of quality content. News short video requires editors to have both strong news literacy and excellent video editing capabilities. In the face of fierce market competition, the best way to move faster is to encourage traditional journalists to transition to the field of video production and specialize in it.

\subsection{The coordinated development of traditional media and distribution platforms}

In recent years, many traditional news media such as "People's Daily" and "Beijing News" have entered the platform media, exploring new ways of developing short video news, and have achieved good results. The two parties should maintain a positive and open attitude, integrate the advantageous resources of both parties, and realize their huge potential.

\subsection{Grasping the agenda setting and social mobilization ability}

Different from traditional media, which follows objective reality, multiple sources of information, and repeated verification, self-media often uses the narrative of individual perspectives to impress readers with details, emotions, and stories, and ultimately achieve the effect of stimulating public emotions and social mobilization. If a video news posted by a media with many fan user is forwarded by another user with a lot of fans, like snowballing, the video content is often a social phenomenon and people's livelihood problem that can resonate with people. In the end, this video will get a lot of attention. At the same time, it attracted the attention of professional media and government departments, and the problem was finally solved by the government. In this way, discovering problems from the media provides professional media with news clues and basis of public opinion. The administrative resources and social influence of professional media promote the resolution of problems.

\subsection{Supervision and self-management by all parties in the society}

The quality of short video news content varies today. How to get rid of rumors and avoid vulgar content is the biggest problem at present. The government department mainly manages the media of the platform through legislation and orders. The platform media should actively guide the positive energy climate and do a good job of content review and optimization push. Media organizations and individuals should not make videos for the purpose of gaining the attention of others, lead by example, be responsible for their own users who care about themselves, and establish a good image and credibility.

\section{Concluding remarks}

In the era of converged media, short video news centered on content materials, social ties, manual editing and algorithm-oriented will also continue to make efforts. In addition, many new forms of employment have been created for the journalism industry, and composite talents have also been favored by society. In the new era, enriching ourselves and telling stories in different ways is a challenge, an opportunity, and a double-edged sword.

\section{References}

1. Wang X. Layout and thinking of TV media news short video in the era of media (in Chinese). New Media Research 2017; (27). doi: 10.3969/j.issn.1671-7597.2017.21.034.

2. Yin J. Content production and dissemination of news short videos in a media-integrated environment: Taking Southern Metropolis Daily’s “Original Video” as an example (in Chinese). Radio TV Journal 2017; (12). 
3. Liu J. The development status and prospects of short video news in China in the era of media (in Chinese). Public Communication of Science Technology 2018; (14).

4. Yin L, Gao H. The development status and spreading trend of short video of traditional media news (in Chinese). Contemporary Communication 2018; (6).

5. Zhang Z, Li A. Changes and challenges in the 6th issue of 2018: Media platform and platform mediaization-2018 China journalism annual observation report (in Chinese). The Press 2019; (1). 